\title{
EXPERIÊNCIA E COMUNICAÇÃO
}

João Paisana

Iremos abordar as relações entre a ideia de tradição e de experiência, considerada esta no seu sentido mais lato. Tomaremos como fio condutor o pensamento hermenêutico de H.G.Gadamer e de H.R.Jauss no que se refere à ideia de tradição.

Segundo pensamos, e como mostraremos, a tradição possui um âmbito bastante mais largo do que aquele que lhe é conferido por ambos os autores; ela não se refere nem actua apenas na experiência hermenêutica, mas em toda a experiência em geral. Nesta medida, os conceitos chave de história dos efeitos (Wirkungsgeschichte) e história da recepção, embora pertinentes, parecem-nos insuficientes para caracterizar a tradição. Cremos que os referidos conceitos necessitam de ser completados e mais claramente articulados através do que denominamos por resposta existencial.

Veremos então, que a tradição não transmite em primeiro lugar,nem predominantemente, obras, escritos, mas comportamentos. São estes que nos permitem compreender em toda a sua extensão o papel dos preconceitos e não apenas a história dos efeitos ou da recepção.

$\mathrm{Na}$ verdade, toda a experiência é igualmente pré-orientada por preconceitos e não apenas a exegese das obras transmiticlas.

Como veremos, os preconceitos que pré-orientam a experiência não são subjectivos nem objectivantes (não são conceitos, nem predicados nem se referem a qualquer determinação ôntica), mas possuem uma dimensão comunicativa. A experiência realiza-se sempre já num espaço público (mundo) de comunicação; não tem pois fundamento falar de experiências privadas ou mudas. A conversação é originária e apenas no seu seio a experiência humana se pode efectuar.

O enunciado de experiência é ante-predicativo e pré- -objectivo, não é um enunciado de conhecimento. O seu sentido objectivo não se funda no conhecimento de um objecto. Por outras palavras, o seu sentido não pode ser determinado pelas suas condições de verdade, entendidas estas através da referência $e$ da predicação.

O sentido de um enunciado de experiência, as suas condições de satisfa- 
ção, implica sempre a relação com um auditório. O enunciado de experiência reenvia sempre para outros possíveis enunciados e não possui um sentido intrínseco, isolado, exterior e anterior à comunicação. Assim o sentido de um enunciado, mesmo de experiência, apenas pode ser determinado através da discussão e do diálogo.

Só quando o enunciado de experiência, de modo derivado, é interpretado predicativamente (logos apofântico) - como verdadeiro ou falso - é que a dimensão comunicativa é posta "fora de circuito", a experiência é reduzida à dimensão cognitiva, abre-se então o caminho para uma concepção da experiência privada ou muda.

\section{I - Situação hermenêutica e tarefa hermenêutica (exegese)}

Tomámos como fio condutor da ideia de tradição o pensamento de H.G.Gadamer e também de H.R.Jauss na sua orientação hermenêutica.

Ambos os autores abordam a tradição a partir da hermenêutica das "ciências do espírito" ou das "humanidades",por oposição às "ciências da natureza": "à auto-compreensão das ciências do espírito coloca-se a exigência de se libertar, na totalidade da sua acção, do modelo das ciências da natureza."1

O estudo da tradição é efectuado a partir da exegese das obras transmitidas pela própria tradição; o que está em questão é sempre a interpretação de textos. A proeminência e o aspecto exemplar, reivindicado por Gadamer, para o estudo das obras clássicas é bem o exemplo do que afirmamos.

A tradição é deste modo encarada, por um lado, através do estudo das obras transmitidas e do "rasto" por elas deixado - a história dos efeitos (Wirkungsgeschichte); por outro, através do estudo do modo como tais obras foram recebidas - a história da recepção. Poderemos afirmar que, dentro da perspectiva hermenêutica a que nos referimos, a história dos efeitos e a história da recepção funcionam como os conceitos chave para a elaboração da ideia de tradição.

Segundo pensamos, a tradição tem um âmbito muito mais vasto do que aquele que é específico à experiência das ciências do espírito ou mesmo das humanidades. Na verdade, ela refere-se a toda a situação histórica humana e, como tal, à totalidade da experiência humana não se cantonando apenas no que poderíamos chamar a "experiência das obras de cultura" transmitidas.

Ao pensar a tradição, sempre a partir do ponto de vista da exegese expressa da hermenêutica das ciências humanas, os autores não distinguem nem articulam com suficiente clareza a situação histórica, a partir da qual a exegese se efectua, e o próprio trabalho de exegese explícita, a tarefa hermenêutica propriamente dita. Os elementos temáticos e os elementos não-temáticos, constitutivos da tradição, não podem assim ser claramente articulados.

Ora, a situação histórica, na qual o homem sempre se encontra, é bem mais geral do que a experiência hermenêutica tal como Gadamer a entende. A tradi- 
ção desempenha um papel fundamental em qualquer situação histórica abrange toda a experiência em geral e é essencial não apenas para a exegese das obras transmitidas e recebidas - porque o homem e o mundo se encontram sempre já existencialmente interpretados através da tradição.

Como veremos, a tradição transmite, em primeiro lugar, comportamentos humanos, isto é, possibilidades de ser no mundo determinadas. É apenas sobre a base destes comportamentos transmitidos que podem igualmente ser transmitidos obras, utensílios, etc., e isto por uma necessidade essencial.

A exegese das obras transmitidas, sobretudo literárias, permite uma abordagem apenas parcial da tradição, quando esta é estudada no seu conjunto. A tradição, enquanto característica de uma situação histórica, não é redutível à história dos efeitos nem à história da recepção das obras, embora a englobe.

Outro aspecto essencial da hermenêutica gadameriana, neste ponto seguido por Jauss, consiste em pensar o trabalho da exegese segundo a lógica da pergunta e da resposta. E neste perspectiva que é pensada a tradição: o texto transmitido é, antes de mais, uma resposta e interpretar um texto consiste em compreendê-lo como resposta a uma questão.

Nós, não só aceitamos este modo de abordar a tradição - segundo a lógica da questão e resposta - como pretendemos radicalizá-lo, através do estudo da resposta existencial. Pretendemos mostrar que esta lógica radica na própria estrutura do modo de ser humano e assim é a própria ideia de tradição que se encontra radicalizada e alargada.

Há um ponto, no entanto, que nos parece insuficientemente formulado por ambos os autores. Esta dificuldade tem origem no facto de não serem suficientemente determinados os elementos temáticos e os elementos não temáticos da tradição, isto é, de não serem suficientemente determinadas e articuladas a situação histórica ${ }^{1}$, a partir da qual se realiza a exegese, e o próprio trabalho da exegese.

Precisemos esta dificuldade: a tradição transmitida deve ser inicialmente recebida, na situação histórica, como uma resposta expressa, isto é, uma resposta obtida a partir da formulação expressa da questão, ou como uma resposta sem questão? isto é, uma resposta desenraízada da questão a partir da qual foi inicialmente formulada? ${ }^{2}$

Esta dificuldade é fundamental, porque todo o rendimento específico da exegese é, através dela, posto em causa. É ela que permite distinguir e articular

${ }^{1}$ Gadamer e Jauss opõem-se apenas na medida em que o primeiro defende que é a própria tradição que coloca a questão ao intérprete, interpelando-o, enquanto o segundo afirma a necessidade de ser o próprio intérprete a colocar a questão: "a história não diz nada, ela responde". No entanto, a relação pergunta/resposta é para ambos o momento essencial da exegese, pese embora as posteriores divergências.

2 Jauss foca esta dificuldade, infelizmente de modo excessivamente rápido, quando nos diz que é apenas a partir do ponto de vista da recepção que um texto pode ser encarado como uma resposta. 
tradição e consciência histórica, que Gadamer parece confundir. Só a assimilação entre tarefa hemenêutica (exegese) e situação histórica (situação hermenêutica) permite ignorar tal dificuldade.

Clarifiquemos a necessidade de distinção dos dois momentos referidos:

Na situação histórica, a partir da qual se realiza a exegese, a tradição transmitida é desenraizada da questão de onde surgiu, a qual não é explícitamente transmitida; ela é, de algum modo, uma resposta sem questão ou, mais exactamente, uma resposta que ao velar a questão de onde surgiu se vela a si própria como resposta. Ela é transmitida na sua mera efectividade, como simples positividade, originando-se assim o carácter autotitário de toda a tradição; esta "encerrou "a questão. Transmite-se e recebe-se a opinião de um autor, de uma autoridade, em simples positividade.

À tarefa hermenêutica, ao inverso, consiste em colocar de modo expícito a questão, a fim de que a tradição transmitida surja como uma resposta expressa. Enquanto resposta explícita a tradição deixa de ser compreendida na sua mera efectividade para passar a ser considerada como simples possibilidade, uma resposta possível entre outras. A questão abre e mantém abertas as possibilidades, as respostas possíveis. A resposta eleita - a transmitida pela tradição - tem agora de justificar a sua possivel proeminência, face a todas as outras possíveis respostas. Isto é, a discussão ou destruição da tradição revela-se assim um momento necessário de toda a exegese filosófica. A tarefa hermenêutica implica não apenas pôr em questão a tradição, mas igualmente discuti-la face a outras respostas possíveis e articular unitariamente tal discussão em direcção à verdade. Só esta destruição da tradição permite o aparecimento da consciência histórica.

Poderemos resumir o que dissemos:

1) É necessário distinguir claramente entre situação histórica (situação hermenêutica) e exegese (tarefa hermenêutica).

2) O modo como a tradição é encarada na situação histórica e na exegese expressa é claramente distinto: no primeiro caso, sob o signo da continuidade, da aceitação; no segundo caso, sob o signo da ruptura, destruição.

3) Se a situação histórica é condição necessária da tarefa hermenêutica, do mesmo modo que a tradição é condição necessária da consciência histórica, ela não é no entanto condição suficiente - é precisamente o rendimento específico da tarefa hermenêutica, da exegese, a transformação da tradição em consciência histórica.

4) Ao inverso, a situação histórica é autómoma, ela não implica necessariamente a realização da exegese expressa, do mesmo modo que a tradição não implica a consciência histórica ${ }^{3}$

${ }^{3}$ Como se sabe, os povos que vivem imersos na tradição, as culturas tradicionais, não têm, no 
Poderemos concluir que a tradição não pode ser pensada apenas a partir da exegese expressa das obras transmitidas ou do modo como foram recebidas pelos seus destinatários, isto é, da tarefa hermenêutica - tal como o fazem Gadamer e Jauss - mas deve ser concebida a partir da própria situação histórica em que o homem sempre se encontra.

Se pretendemos pensar a tradição através da lógica da pergunta e da resposta então devemos caracterizá-la como uma resposta sem questão, como uma resposta que, ao velar a questão a partir da qual surgiu, se vela a si mesma como resposta. É apenas ao nível da exegese expressa (não da situação histórica) é que a tradição pode ser caracterizada segundo a relação pergunta-resposta explicitas; mas então situamo-nos já a um nível derivado, dependente que, como tal, falha uma caracteristica essencial da tradição, a saber: a tradição tem uma dimensão comunicativa, mas trata-se de uma comunicação distorcida.

\section{II - A resposta existencial}

Será assim necessário, ainda que de modo bastante rápido, esboçar sucintamente como entendemos a experiência.

A experiência é sempre e já experiência no mundo (na verdade, num mundo articulado pela linguagem). Longe que a experiência seja o que nos permite o acesso inaugural ao mundo, toda a experiência é já experiência no mundo, que ela pressupõe como sua própria condição ${ }^{4}$.

Agora bem, o homem encontra-se no mundo sempre num modo de ser determinado, nunca num modo neutral, essencial ou em simples passividade (onticamente indeterminado).

Compreendendo-se a partir das suas possibilidades de ser no mundo, o homem encontra-se sempre já lançado, junto ao ente, numa possibilidade de ser fáctica, enquanto fundamento do não-ser das outras possibilidades.

Assim nunca se encontra num modo de ser neutro ou essencial, indiferente quanto à sua modalidade, mas encontra-se sempre num modo de ser determinado, indissociavelmente como fundamento do não ser das suas outras possibilidades. Poderemos dizer que o homem se encontra sempre como tendo já respondido existencialmente à questão que interroga pelo sentido histórico do seu ser no mundo.

sentido próprio do termo, consciência histórica; tal não significa que não possuam relação com o passado, significa apenas que tal relação não é temática, mas meramente existencial (Mircea Elíade - Initiations, rites et sociétés secretes, Gallimard, Paris, 1959, p. 15)

${ }^{4}$ Não iremos agora justificar esta afirmação. A questão que se deverá colocar não consiste em determinar como temos acesso ao mundo através da expriência, mas, ao inverso, deveremos perguntar como foi historicamente possível colocar a questão sob esse modo tão essencialmente inexacto. Longe que a referida pergunta seja originária e possa servir de ponto de partida, ela só poderá mesmo ser formulada a partir de uma interpretação derivada e parcial da experi ência. (J. Paisana "Discurso científico e poético na filosofia de Aristóteles" in Philosophica 9, Dep. Filosofia da F.L.U.L. 1997, pp 77/ 93. 
Se questionar é abrir possibilidades, isto é, abrir as múltiplas respostas possíveis ao que está em questão, por sua vez, responder é encerrar possibilidades, isto é, eleger uma dessas possibilidades enquanto fundamento do não-ser das outras. A possibilidade eleita, a resposta afirmada, opõe-se a todas as outras possiveis respostas abertas pelo questionar; uma vez que o homem se encontra sempre já lançado numa possibilidade de ser fáctica, histórica, enquanto fundamento do não-ser das outras possiveis projecções históricas, afirmamos que o homem se encontra sempre como tendo já respondido existencialmente à questão sobre o sentido histórico do seu ser no mundo. É esta dimensão fundamental da existência que chamamos resposta existencial.

Poderemos esclarecer o que dizemos através da referência ao carácter histórico da existência humana e do mundo no qual ela sempre se encontra.

Se o homem é um ser histórico e, como tal, está sempre já historicamente situado, isto não significa apenas que a existência humana esteja passivamente submersa na história, submetida à simples efectividade do fluir histórico; ao inverso, ela também se compreende sempre já historicamente, compreende-se a partir das suas possibilidades de ser (históricas) não as sofrendo simplesmente no seu passar efectivo.

O homem advém a si historicamente a partir de uma eclosão e de uma privação de possibilidades; no entanto, as possibilidades abertas, através das quais o homem se compreende, são sempre em excesso relativamente àquelas que pode historicamente efectivar ${ }^{5}$

As possibilidades abertas, devido à finitude humana, isto é, precisamente em virtude do seu carácter temporal, nunca se poderão efectivar em totalidade. Ao efectivar, de modo fáctico, uma determinada possibilidade, o homem já prescindiu e teve de prescindir de outras possibilidades.

Deste modo,devido à estrutura da existência humana, porque histórica, o homem advém a si de forma essencialmente questionante, questionante quanto á sua determinação, quanto á sua efectivação histórica ${ }^{6}$. Compreende-se que Heidegger, ao considerar a temporalidade finita como o sentido do ser do existente humano (Dasein) nos afirme que deveremos caracterizar o Dasein como o ente que tem o seu ser em questão, ou cuja estrutura é a questão do seu ser?

Mas se a existência humana se compreende historicamente de modo questionante, notemos que não se trata de uma questão teórica ou mesmo temática, mas de uma questão existencial.

${ }^{5}$ É o que permite que uma actividade política possa ser planeada, por exemplo.

${ }^{6}$ Recordemos que Lenine, ao tentar compreender a situação histórica da Rússia pré-revolucionária, questionava: Que fazer? A própria história só advem como questão.

${ }^{7}$ Sein und Zeit, Max Niemeyer, Tuebingen, 1972; Vom Wesen des Grundes, V. Klostermann, Frankfurt. 
À questão colocada pela história o homem não pode responder tematizando explicitamente as suas possibilidades de ser elegendo, de modo a-histórico, uma entre outras, tornando-a então histórica. A história, no seu fluir, não pára a fim de que o homem se possa decidir, de modo a-histórico, por uma ou por outra possibilidade. À questão existencial que a história continuamente coloca, o homem pelo simples facto de existir, e existindo numa possibilidade de ser fáctica enquanto fundamento do não-ser das outras possibilidades, já respondeu, já respondeu existencialmente. A existência, devido à sua finitude, não tem a possibilidade de não responder quanto à historicidade do seu ser, quanto ao sentido histórico do seu ser no mundo. A questão existencial não é pois uma questão subjectiva (que possa ser subjectivamente colocada). $O$ homem não existe primeiro para, posteriormente, poder colocar a questão; ao inverso, a sua existência só é possivel na medida em que já respondeu a uma tal questão trans-subjectiva.

À realidade humana não é possível a eleição de possibilidades históricas a partir de um modo de ser neutro ou essencial, indiferente quanto à sua modalidade, isto é, exterior ou anterior à própria história; ela apenas pode existir de modo finito, sempre num modo de ser determinado.

O modo de ser histórico, enquanto possibilidade de ser fáctica, determinada, finita, em que sempre já se encontra a existência humana pelo simples facto de existir, não pode ser compreendido apenas na sua mera efectividade, em pura positividade - no mero fluir constante da história - mas, porque ele é indissociavelmente o fundamento do não-ser de outras possibilidades, ele é sempre já uma resposta, não temática, à questão que a própria história, na abertura de possibilidades, coloca.

O homem encontra-se sempre existencialmente já respondido, isto é, de modo não temático, não expresso. A questão não foi expressamente formulada e a resposta existencial não surge como resposta expressa.

Poderemos dizer que, tendo já respondido à questão sobre o sentido do seu ser, o homem se encontra sempre historicamente auto-interpretado, interpretado não a partir da formulação explícita da questão, mas interpretado a partir de uma tradição, por meio da educação, da linguagem, da cultura, quaisquer que elas sejam. Ao auto-intrerpretar-se existencialmente o homem veicula assim uma tradição, não de modo temático e consciente, isto é, como um conjunto de conhecimentos, mas como um conjunto de preconceitos que orientam toda a sua relação com o mundo.

Uma vez que a resposta existencial não é obtida a partir da formulação da questão expressa, ela é obtida a partir de uma tradição.Toda a resposta existencial veicula assim uma tradição.

A tradição transmite, em primeiro lugar, comportamentos. Se o modo de ser em que o homem sempre se encontra, enquanto possibilidade de ser fáctica, é uma resposta (existencial) obtida, não a partir da tematização expressa da questão, mas a partir da tradição, tal significa que a tradição transmite fundamentalmente 
possibilidades de ser no mundo determinadas, isto é, comportamentos. "Os comportamentos dos homens e dos deuses constituem os temas dos relatos épicos"8 diz-nos Homero. O que é transmitido originariamente pela tradição são comportamentos humanos, possibilidades de ser, não descrições ou constatações; por isso a tradição reveste inicialmente o modo da narrativa.

\section{III - Tradição e comportamento}

Ao contrário do pretendido po $\mathrm{H}$. Gadamer, os elementos essencialmente transmitidos pela tradição não são obras, literárias ou artísticas, utensílios ou quaisquer outros "testemunhos" do passado; ao inverso, se os comportamentos não forem previamente transmitidos e com eles uma pré-compreensão do mundo, os entes encontrados como pretensos "testemunhos" do passado, mostram-se impotentes para veicular uma tradição". Se a leitura e a escritura não forem transmitidas previamente como possibilidades do ser humanas no seio de uma dada tradição, por exemplo, o escrito nunca poderá ser encontrado como "o objecto preferente da hermenêutica"10; numa comunidade que desconhecesse a leitura e a escritura como possibilidades de ser, o ente encontrado - para nós "enquanto escrito" - seria percebido "enquanto tal ou tal" mas nunca "enquanto escrito". Deste modo, não podemos aceitar a afirmação de Gadamer segundo a qual o facto de que "essência da tradição se caracteriza pela sua linguisticidade (Sprachlichkeit) torna-se manifesta na sua plena significação hermenêutica, onde a tradição se torna escrita"11 $\mathrm{Na}$ verdade,como mostram as investigações antropológicas, as comunidades que desconhecem a escrita são aquelas que mais fortemente se encontram veiculadas pela tradição.O mesmo poderemos dizer relativamente a utensílios, objectos de culto, etc., que apenas em função de determinadas possibilidades de ser, comportamentos trasnmitidos pela tradição, podem surgir precisamente enquanto utensílios ou instrumentos.

A um primeiro nível a tradição é constituída por elementos não temáti$\cos ^{12}$, os preconceitos (do interprete) veiculados por possibilidades de ser deter-

8 Odisseia 1,338, citado por Hermann Fraenkel in Dichtung und Philosophie des fruehen Griechentums (trad. cast. Sanchez Ortiz), visor, 1993, p. 64. Do mesmo modo diz-nos Aristóteles na Poética (1450a) a propósito da tragédia, que encontra os seus temas na tradição: "o elemento mais importante é a trama dos factos, pois a tragédia não é imitação de homens, mas de acções (comportamentos) e de vida.".

9 Recordemos as dificuldades encontradas pelos arqueólogos para identificar alguns utensílios descobertos e qual a sua função, uma vez que os comportamentos para os manipular não foram transmitidos; os "vasos canopos" dos egipptólogos são disto um bom exemplo. Kant refere algo análogo na Crítica da faculdade de julgar.

${ }^{10}$ H Gadamer Wahrheit und Methode, Paul Siebeck, 1990

11 Ibid., p. 367

$12 \mathrm{Na}$ verdade Gadamer põe em destaque os preconceitos do intérprete como momentos essenciais da exegese; no entanto, parece pretender compreendê-los apenas a partir da história dos efeitos, 
minadas, que caracterizam a situação histórica como situação hermenêutica, na qual pode então tomar lugar a história dos efeitos (Wirkungsgeschichte) e a história da recepção das obras transmitidas - elementos temáticos de tradição. Deste modo, os elementos não temáticos da tradição, os preconceitos, não podem ser compreendidos apenas a partir da história dos efeitos e da história da recepção, isto é, a partir das obras, mas exigem com necessidade a consideração da resposta existencial. Relativamente à experiência a tradição tem assim um âmbito bem mais vasto do que aquele que se confina à experiência hermenêutica, tal como H.Gadamer e H.R. Jauss a entendem.

\section{IV - Preconceito e resposta}

Podemos assim afirmar: todo o modo de ser em que o homem encontra o ente - a experiência - é a um tempo; por um lado, tematicamente, de modo explícito, um comportamento; por outro, implicitamente, de modo não temático, uma resposta, que veicula uma tradição.

È através de tais comportamentos, deste modo transmitidos, que o homem encontra o ente. O "estado de descoberto" do ente, tal como ele é encontrado na experiência, não é um simples dado bruto, mas reenvia já para possibilidades humanas de ser no mundo. Agora bem, na medida em que o comportamento é uma possibilidade de ser enquanto fundamento do não-ser das outras possibilidades, o homem encontra o ente não num modo de ser neutro ou em pura passividade (tabula rasa), mas sempre pré-orientado através de uma antecipação de sentido, através de preconceitos. A experiência é então orientada por antecipações que nos permitem encontrar o ente segundo a estrutura algo enquanto algo e nunca como um $X$ indeterminado; poderemos mesmo afirmar que esta estrutura "enquanto que" constitui a estrutura fundamental da experiência. O ente encontrado na experiência surge enquanto àrvore, enquanto livro, etc., mas nunca na sua pura entidade ${ }^{13}$. Oiço a canção da cantora e não sinto simples sons, vejo um livro de capa azul sobre a mesa e não sofro obscuras sensações de $\operatorname{cor}^{14}$. A mais

isto é, do rasto deixado pelas obras. As obras transmitidas ocupam assim um lugar proeminente face aos comportamentos.

13 Recordemos que para os Escolásticos a substância nunca se dá na sua substancialidade, mas apenas segundo os seus atributos ou determinações.

Do mesmo modo B. Russell ao contrapor os simples (que Russell explicitamente aproxima da noção aristotélica de substância primeira - sujeito de predicados que não pode ser predicado de nenhum sujeito) aos factos (complexos de estrutura predicativa que apenas podem ser afirmados ou negados, mas não nomeados), reconhece que relativamente aos simples está "falando de algo que, enquanto tal, não é objecto de experiência." "Logical Atomism" (1924) in Logic and Knowledge. Essays 1901-1950, Georges Âllen and Unwin, London, 1956

${ }^{14}$ Naturalmente que não iremos discutir agora o papel desempenhado na experiência pelos pretensos dados sensiveis que a constituíriam ou, pelo menos, the serviriam de primeiro substracto. Necessitaríamos de alcançar previamente uma correcta compreensão da experiência para, posteriormente, podermos esclarecer como foi possível colocar a questão de modo tão inexacto. 
simples experiência, porque pré-orientada, implica preconceitos, pontos de vista prévios sobre o ente.

Notemos, no entanto, que estas anticipações de sentido, estes preconceitos que orientam a experiência, não têm alcance meramente subjectivo. O enunciado de experiência não comunica o modo como o sujeito é afectado pelo ente. Por exemplo, quando digo:"a árvore é alta," o martelo é pesado", a "rocha é dura", tal não significa que eu sinto subjectivamente o peso do martelo, a altura da árvore, ou a dureza da rocha, etc.

Os preconceitos, tal como os referimos, exprimem a articulação entre experiência e tradição. A tradição pode mesmo ser caracterizada como um conjunto de preconceitos que orienta a nossa relação no mundo.

Como dissemos, a tradição transmite em primeiro lugar comportamentos (que determinam os preconceitos) os quais são na verdade respostas, mas estas respostas são desenraízadas das questões de onde surgiram; poderemos assim caracterizar a tradição como uma resposta sem questão ou, mais exactamente, como uma resposta que ao velar a questão se vela a si mesma como resposta. $\mathrm{O}$ conjunto de preconceitos (tradição) que orienta o comportamento humano é constituído por respostas passadas e sedimentadas, transmitidas na sua efectividade, sem que as questões de onde surgiram tenham sido igualmente transmitidas de modo explícito. Assim as tradições são transmitidas como preconceitos e não como conhecimentos. Poderemos dizer que a tradição transmite as respostas desenraízadas das questões. É precisamente esta ocultação das questões, momento essencial da tradição, que permite a esta dissimular a sua dimensão comunicativa e afirmar -se de modo autoritário (pretendendo inviabilizar qualquer possibilidade de diálogo), - a tradição não se discute, cumpre-se! ${ }^{15}$ A tradição tem assim uma dimensão comunicativa, organizada segundo a estrutura pergunta/resposta, mas trata-se então de uma comunicação distorcida ${ }^{16}$.

Embora se trate de uma comunicação distorcida, a sua dimensão comunicativa mantém-se. Com efeito, todo o modo de ser em que o homem encontra o ente, na experiência, na medida em que é um comportamento transmitido pela tradição, é já uma resposta a uma questão comum, pública, trans-subjectiva, embora não formulada expressamente, mas transmitida de modo implícito pela tradição.

Devido à sua articulação com a tradição, a experiência implica no seu seio,

15 “A Pátria não se discute, defende-se!", afirmava a palavra de ordem do nacionalismo fascizante. A pátria não se põe em questão, é inquestionável (em nome da tradição) - tal ilustra bem o que dizemos. Na verdade, a pátria, uma resposta às relações entre o homem e o mundo, pretende não só velar a questão a partir da qual surgiu como, ao tornar-se inquestinável, velar o seu próprio carácter de resposta.

16 A resposta existencial, que veicula a tradição, transmite comportamentos, isto é, possibilidades de ser no mundo. Estes comportamentos são tematicamente transmitidos na sua efectividade, quando na verdade são uma simples possibilidade (uma resposta possível entre outras) enquanto respostas encerram possibilidades e, como tal, são preconceitos. 
com necessidade, uma dimensão comunicativa. Ela refere-se sempre a uma comunidade de comunicação, aglutinada por questões comuns, veiculadas por uma mesma tradição.

Não tem pois sentido falar de experiências privadas (ou mudas), isto é, anteriores à sua dimensão comunicativa. A questão que se coloca consiste em determinar como foi historicamente possível formular as dificuldades relativas à experiência de modo tão pouco claro ${ }^{17}$

A experiência não se realiza no espaço encerrado da subjectividade, não é algo que se passa no interior do sujeito cognitivo; a experiência realiza-se sempre no seio do mundo trans-subjectivo, público (poderíamos dizer mundo cultural, se a expressão não fosse tautológica). Quando Locke nos afirma que "entendo por qualidade a causa de uma ideia simples no meu espirito"(Draft A \&2, Nota) parece-nos claramente que inverte os termos da questão; o amarelo que experiencio não é uma "ideia simples" privada, mas antes de mais, algo que surge no mundo público, trans-subjectivo; é o amarelo do anel ou a cor da camisola do futebolista.

A experiência não trata de estabelecer a minha relação inaugural, a origem misteriosa, da minha relação individual com o mundo; ela é sempre e já experiência num mundo público.

O preconceito, a antecipação de sentido que orienta a experiência, na medida em que é determinado pelo comportamento,que já é uma resposta a uma questão comum, não tem pois carácter subjectivo - interpretar um enunciado, mesmo de experiência, é como nos diz Gadamer, compreendê-lo como resposta a uma questão comum a locutor e auditório, situando-se sempre no espaço de diálogo de uma mesma tradição.

\section{V - A dimensão comunicativa da experiência}

Mas o preconceito não é igualmente objectivante. O preconceito não pode ser considerado como um autêntico conceito ou como um predicado, ele não se refere a qualquer propriedade ôntica do ente. Na verdade o preconceito não determina, nem sequer se refere a um objecto de conhecimento, uma vez que a experiência é ante-predicativa e pré-objectiva ou, melhor, pré-objectual.

O preconceito não é um conceito: ele não se pode pensar como a combinação de actos subsumidores em virtude dos quais algo particular é integrado sob uma ideia geral. O preconceito não subsume o particular sob o universal e, como tal, não é determinante. Por exemplo, os enunciados de experiência: "a árvore é alta" ou o "martelo é pesado", não significam que o conceito de altura ou de peso subsumam sob si os objectos àrvore ou martelo, ou mesmo que os

$17 \mathrm{O}$ fio condutor que nos permitiria esclarecer tal questão ser-nos-ia dado pelo primado, quase exclusivo, concedido ao enunciado predicativo (logos apofântico) desde Aristóteles (Da Interpretação - 4, 17a) 
conceitos de altura ou de peso surjam como propriedades dos entes encontrados na experiência.

O preconceito não é igualmente um predicado. Ele não surge como determinante face ao ente que seria o determinado, determinado como sujeito de predicados, isto é, como objecto. O enunciado de experiência é, como dissemos, ante-predicativo e pré-objectivo (pré-objectual); ele é irredutível ao Logos apofântico, ao enunciado predicativo, precisamente por isso ele não possui originalmente uma dimensão teórica, cognitiva ${ }^{18}$.

O "estado de descoberto" do ente encontrado na experiência é pré-orientado por uma antecipação de sentido, por um preconceito, o qual é determinado por um comportamento, isto é, por uma possibilidade humana de ser no mundo, que é já uma resposta a uma questão implícita, transmitida por uma tradição. O "estado de descoberto" do ente encontrado não pode então ser fundado pelo próprio ente, como sua propriedade ôntica, mas reenvia, com necessidade para "fora dele", para as possibilidades humanas de ser no mundo e para a tradição por elas veiculada.

A experiência não conduz directamente ao objecto, o que é encontrado de modo imediato na experiência deverá antes ser caracterizado como ente disponível ou como utensílio, isto é, ente intramundano. Assim deveremos afirmar que a experiência não tem fundamentalmente, e muito menos exclusivamente, uma dimensão teórica, de conhecimento. O sujeito da experiência não pode ser caracterizado como sujeito cognitivo e o estudo da própria experiência deve abandonar o ponto de vista que privilegia, de modo unilateral, a dimensão do conhecimento.

Agora bem, se considerarmos que o sentido objectivo de um enunciado se determina através das suas condições de verdade, então pretendemos dizer que tais condições, mesmo no caso de um enunciado de experiência, não podem ser determinadas apenas através da referência e da predicação ${ }^{19}$. É exactamente o que afirmamos quando dizemos que o enunciado de experiência é ante-predicativo ${ }^{20} \mathrm{e}$, porque ante-predicativo, pré-objectivo ${ }^{21}$.

18 Recordemos o que nos diz Aristóteles no tratado Da Interpretação, 4, 17a: "todo o enunciado (logos) tem uma significação (semântikos) ... mas nem todo o enunciado é predicativo (apofântikos); só o será aquele de que é pertinente dizer que é verdadeiro ou falso, o que não se produz em todos os casos: assim a prece é um enunciado, mas ela não é verdadeira nem falsa. Deixemos de lado este género de enunciados; o seu exame é sobretudo a tarefa da Retórica ou da Poética. É a predicação que iremos agora considerar."

19 No caso de o enunciado ser entendido unicamente como predicação, então o juízo é o lugar da verdade apofântica. A predicação, tomada como um todo, é verdadeira no caso preciso em que o termo predicado se aplica ao objecto a que o termo sujeito se refere. A verdade pode assim ser estabelecida pela fundamentação do predicado no sujeito, como adequação do predicado ao referente do sujeito

20 Naturalmente que, do ponto de vista estritamente sintáctico, poderemos sempre descrever os enunciados em questão como relação de um sujeito e de um predicado; no entanto, do ponto de vista semântico (o que aqui está em discussão, uma vez que se trata da determinação do 
Exemplifiquemos com os seguintes enunciados de experiência: a) "a árvore é alta"; b)"o martelo é pesado"; c)"a rocha é dura ".

No primeiro caso, "a árvora é alta": é apenas se me encontro sentado no escritório e pretendo observar algo que se passa ao longe no horizonte, é que a árvore que aparece através dos vidros da janela surge enquanto alta, se me obstrui total ou parcialmente a visão do que pretendo observar. É apenas em função de um comportamento (visão longínqua) que antecipa um sentido, que o ente encontrado (árvore) se descobre enquanto tal ou tal (alta).

Consideremos agora o exemplo "o martelo é pesado": é apenas em função da tarefa que me proponho realizar (comportamemto) é que o ente encontrado (martelo) através de uma antecipação de sentido surge enquanto pesado. se me proponho reparar um relógio de pulso com um martelo de pedreiro este surge enquanto demasiado pesado; ao inverso, se com o mesmo martelo pretendo espetar no solo uma estaca de grandes dimensões, ele surgirá enquanto demasiado leve.

O mesmo poderemos dizer a propósito do terceiro exemplo.

No entanto, e este é o ponto essencial, em nenhum dos casos se trata de uma pura constatação. Nenhum dos exemplos apontados pode ser encarado como um simples enunciado predicativo.

A análise dos enunciados referidos, efectuada através do simples estudo da relação estabelecida entre sujeito e predicado, revela-se manifestamente insuficiente para determinar as suas condições de verdade, o seu sentido. O "estado de descoberto "("alta", "pesado" "dura") não é uma propriedade do objecto ("árvore", "martelo", "rocha") de modo a poder ser descrito pela atribuição de um predicado a um termo sujeito que refere esse objecto.

Será apenas em conformidade com um comportamento humano - enquanto obstrui a visão, ou enquanto se descobre innadequado para determinada tarefa que o ente encontrado (árvore,martelo), a partir de uma antecipação de sentido, é descoberto enquanto tal ou tal (alta,pesado); mas este "estado de descoberto" não pode ser considerado uma sua propriedade intrínseca ou determinação ôntica. Por isso dissemos que o ente encontrado na experiência reenvia para "fora dele".

Poderemos assim concluir que se um enunciado de experiência possui sentido objectivo, isto é, é válido para todos os sujeitos, as suas condições de satisfação, que lhe determinam esse sentido, não podem ser satisfeitas apenas a partir da consideração de um objecto e dos seus atributos (predicados), como no caso do enunciado teórico. Nesta medida o enunciado de experiência não é objectivante, não se refere a um objecto ou, mais precisamente, é pré-objectual, o que não significa que não tenha sentido objectivo (universal), significa apenas que a sua validade objectiva não se funda no conhecimento de um objecto.

sentido), a sua caracterização através da referência e da predicação mostra-se claramente insuficiente pois não permite determinar as suas condições de verdade.

21 Com efeito, o objecto é o sujeito de possíveis predicados. 
Encontramo-nos assim, partindo do estudo da experiência em geral, bastante próximos do juízo de gosto kantiano, pré-conceptual e pré-teórico, e das suas dificuldades. Precisemos a formulação desta dificuldade:como um enunciado de experiência que não possui uma dimensão cognitiva, cuja objectividade não é fundada no conhecimento do objecto, não fica encerrado na subjectividade e pode pretender uma dimensão objectiva (subjectivamente necessária e universal)?

Mas se a questão que colocamos é bastante próxima da questão kantiana, não podemos de modo algum aceitar a resposta proposta por Kant. Como vimos, devido à articulação entre experiência e tradição, não há experiências privadas (nem mudas) - a experiência não é o que nos dá um acesso inaugural ao mundo, ao inverso, toda a experiência se realiza já no seio de um mundo público, trans-subjectivo; se podemos concordar com Kant sobre o carácter pré-conceptual, não teórico, de uma experiência, tal não significa que esta experiência se encerre na subjectividade, isto é, que se reduza à experiência esté$t_{i c a^{22}}$. É o próprio modo como Kant coloca a questão que nos parece essencialmente incorrecto. Não se pode tomar como ponto de partida um sujeito encerrado em si, desprovido de mundo, para, posteriormente, se perguntar pela objectividade da experiência. Na verdade, é sempre já no seio de uma comunidade de comunicação, situada num mundo público, trans-subjectivo, e aglutinada por questões comuns (transmitidas de modo implícito por uma mesma tradição), que o sentido objectivo da experiência pode ser questionado

Como vimos, o enunciado de experiência comunica a conformidade (ou não conformidade) do ente encontrado, a partir de uma antecipação de sentido, com um comportamento determinado. Mas como este comportamento é já uma resposta a uma questão comum (embora implícita) transmitida pela tradição, o enunciado situa-se sempre no interior de um espaço de diálogo.

\section{VI - A dimensão comunicativa da experiência (continuação) $O$ papel da tradição.}

Como vimos, no início do nosso estudo, a significação do mais simples enunciado de experiência não se encerra no ente encontrado, mas reenvia para possíveis comportamentos humanos e para o mundo como horizonte desses comportamentos.

Deste modo a significação do enunciado de experiência não pode ser determinada numa exclusiva orientação objectivante, através da referência e da

22 Diz-nos Kant: "Para distinguir se uma coisa é bela ou não, nós não relacionamos por meio do entendimento a representação ao objecto em vista de um conhecimento, mas relacionamo-la por meio da imaginação (talvez ligada ao entendimento) ao sujeito e ao sentimento de prazer ou desprazer deste. O juízo de gosto não é pois um juízo de conhecimento; assim ele não é lógico mas estético; o que significa aquilo cujo princípio determinante não pode ser senão subjectivo. Kritik der Urteilkraft \& 1. 
predicação; a significação como determinação das condições de verdade dos enunciados, em exclusiva orientação para os "estados de coisas" no mundo, mostrou-se insatisfatória.

Poderemos dizer que há "algo que falta" na exclusiva orientação objectivante, caso ela seja possível, para que a determinação da significação dos enunciados de experiência seja exequível. E, no entanto, manifestamente tais enunciados podem ser claramente comunicados por um locutor e facilmente interpretados por um auditor.

Será necessário tomar em consideração algo comum a locutor e auditor para além do ente intramundano encontrado - para que a interpretação da significação seja possível.

Foi neste ponto que o papel desempenhado pela tradição nos pareceu bastante esclarecedor, o que motivou uma digressão crítica a fim de melhor articular e clarificar o próprio conceito de tradição, reformulando-o.

Ao transmitir comportamentos que são respostas a questões comuns a locutor e auditório, a tradição torna patente a dimensão comunicativa dos preconceitos que pré-orientam a mais simples experiência. Assim afirmámos que o preconceito não é subjectivo nem objectivante, mas possui uma dimensão comunicativa.

Com efeito, afirmar que a experiência, o encontro do ente, implica sempre uma resposta a uma questão exitencial trans-subjectiva, veiculada por uma tradição, é afirmar que a experiência possui sempre uma dimensão comunicativa, que é reflectida no próprio enunciado enquanto acto de fala. Se recordarmos a distinção proposta por John Austin ${ }^{23}$ e desenvolvida, de modo um pouco alterado, por John Searle ${ }^{24}$ entre o carácter locutório ou proposicional e o carácter ilocutório em todo o acto de fala, pensamos que é esta dupla orientação, ôntica e comunicativa, que está verdadeiramente em questão $0^{25}$.

23 J. Austin - How to do things with words, Oxford University Press, 1962, sobretudo VIII e IX conferências.

24 J. Searle - Speech Acts, Cambridge University Press, 1969 e Expression and Meaning, Cambridge University Press, 1979

Após ter referido os seguintes exemplos pronunciados por um locutor para um auditor: "1) João fuma muito. 2) Jão fuma muito? 3) Fuma muito, João! 4) Apraza ao céu que João fume muito!" J. Searle prossegue: "Assim nós isolamos as noções de referência e predicação daquelas que reenviam a actos de linguagem completos tais como a asserção, a questão a ordem, etc., e a justificação desta separação repousa sobre o facto que a mesma referência e a mesma predicação podem encontrar-se realizadas em actos de linguagem completos diferentes. Austin baptizou estes actos de linguagem completos com o nome de <actos ilocutórios> e é este termo que utilizarei doravante. Eis alguns verbos designando actos ilocutórios: <afirmar>, <descrever>, <assertar>, <advertir>, <notar>, <comentar>, <comandar>, <ordenar> ..."-Speech Acts, p. 60/I

$\mathrm{E}$ ainda "os actos proposicionais nunca aparecem isolados, isto é, não se pode unicamente referir ou predicar sem fazer uma asserção, pôr uma questão, ou executar qualquer outro acto ilocutório." id. 63.

25 A propósito da dimensão comunicativa do carácter ilocutório do acto diz-nos J. Searle: "No 
O enunciado de experiência não se limita a referir o ente no "estado de descoberto", mas implica indissociavelmente uma resposta a uma questão trans-subjectiva (pressupondo um auditório implícito); enquanto resposta a uma questão a sua orientação ôntica é indissociável da sua orientação a um auditório questionante implícito - a tradição ${ }^{26}$.

Deste modo, para determinar a significação de um enunciado de experiência será necessário tomar em consideração esta dupla orientação. Diz-nos J. Habermas, "compreender uma expressão <Ausdruck> é saber de que modo alguém pode servir-se dela, para se entender <verstaendingen>com alguém sobre algo."27.

Naturalmente que este duplo aspecto é indissociável, não é possível determinar isoladamente a significação do conteúdo proposicional ou locutório de um enunciado de experiência e, posteriormente, acrescentar-lhe a dimensão comunicativa ou o carácter ilocutório. Nos exemplos anteriomente referidos, "o martelo é pesado", "a árvore é alta", não é possível determinar a significação de um putativo conteúdo proposicional independentemente da dimensão comunicativa; é apenas na medida em que o "para que" - a partir do qual o "com que" me encontro surge "enquanto tal" - é compreendido como resposta (martelar) a uma questão comum a locutor e auditor que a significação do enunciado pode ser interpretada ${ }^{28}$.

caso dos actos ilocutórios conseguimos realizar o que queremos levando o nosso interlocutor a conseguir reconhecer o que procuramos fazer. Mas o <efeito> produzido sobre o auditor não é uma crença, nem uma reacção, consiste simplesmente para o auditor em compreender o que diz o locutor. É este efeito que até aqui chamei efeito ilocutório.", Ibid. p. 88

26 Segundo pensamos, é este carácter implícito de resposta a uma questão, comum a todos os enunciados, que determina o nível ilocutório comum a todos os actos de fala, o qual pode ser posteriormente especeficado.

Diz-nos ainda J. Searle: "Predicar uma expressão $\mathrm{P}$ a propósito de um objecto $\mathrm{R}$, é levantar a questão da verdade da expressão predicativa ao objecto ao qual é feita referência." Ibid.p. 173. E ainda mais claramente: "A caracterização da predicação segundo a qual predicar é <levantar a questão de... > não especifica um acto distinto, mas apenas o que é comum a todos os actos ilocutórios nos quais um conteúdo dado pode aparecer.” p. 175 (os sublinhados são nossos)

27 J. Habermas - Nachmetaphysisches Denken, Suhrkamp, Frankfurt, 1988, p. 128

28 Em Renewing Philosophy, Harvard University Press, 1994, cap. I, diz-nos H.Putnam: “A indução e toda a cognição pressupõe a capacidade de reconhecer semelhanças entre as coisas; mas as semelhanças não são de modo algum elementos constantes do estímulo físico, nem simples padrões de informação recebida pelos sentidos... O que torna as facas semelhantes, por exemplo, não é que todas sejam iguais (não o são), mas que todas estão feitas para cortar ou serem espetadas, e um sistema que possa reconhecer uma semelhança relevante entre as facas tem que ser capaz de atribuir propósitos aos agentes. Os seres humanos não encontram dificuldades para o fazer... é possível que tenhamos uma capacidade "programada" de "colocar-nos no lugar" de outras pessoas que nos permita atribuir a estas todo o propósito que sejamos capazes de atribuir-nos a nós próprios"; no mesmo sentido J. Searle (Expression and Meaning, cap. V, \& 3) afirma: “A tese que avancei é que, para um grande número de frases, o locutor não sabe, pela sua competência linguística, como aplicar o sentido literal de uma frase senão sobre a base comum (Background) de outras assumpções. Se é assim, esta ideia implica 
Na verdade, J. Austin. J. Searle e, posteriormente, J. Habermas e K. O. Apel, entre outros, admitem a referida separação isolando claramente a componente proposicional da componente comunicativa no acto de fala; mas tal só é possível porque estes autores consideram tacitamente ö primado do enunciado predicativo, o logos apofântico, pressupondo já a distinção entre referência $e$ predicação, isto é, pressupondo já a constituição do objecto ${ }^{29}$.Ora, ao nível em que nos encontramos, do enunciado de experiência pré-predicativo e anterior à constituição do objecto, a distinção entre referência e predicação é ainda destituída de sentido. Se tentarmos determinar a significação do enunciado "a árvore é alta", o termo "alta" não é o predicado, nem o termo "arvore" o sujeito; o termo "alta" não se aplica a uma propriedade do objecto a que o termo "árvore" se refere. $\mathrm{O}$ ente intramundano, na sua disponibilidade, ainda não se constituiu como objecto. Como veremos mais tarde, este será precisamente o "rendimento" da predicação, mas só então se poderá falar com propriedade de referente.

Ora, o papel desempenhado pela tradição na experiência, tal como a caracterizámos, permite encarar simultaneamente o nível ôntico e o nìvel comunicativo no enunciado de experiência.

A tradição transmite,de modo temático,comportamentos e, de modo não temático, respostas a questões existenciais. São estas questões, comuns a locutor e auditor no seio de uma mesma tradição, que permitem ao auditor interpretar o enunciado imediatamente (embora de modo implícito) como uma resposta, resposta às questões que a ele próprio foram transmitidas (de modo não temático).

Poderemos assim dizer que interpretar um enunciado, determinar-lhe a significação, é compreendê-lo a partir de uma resposta a uma questão comum a locutor e auditor. Trata-se de se entender com alguém sobre algo no seio de uma mesma tradição. Enquanto enunciado sobre algo enquanto algo, o enunciado tem uma orientação ôntica, enquanto resposta tem uma orientação comunicativa, as quais são indissociáveis.

que não existe distinção rigorosa entre a competência linguística do locutor e o seu conhecimento do mundo." e ainda em Intentionality, Cambridge University Press, 1983, p. 145:"A base comum (Background) é o conjunto de capacidades mentais não representativas que é a condição de que toda a representação tenha lugar.. Os estados intencionais apenas têm as suas condições de satisfação e apenas são os estados que são porque repousam sobre uma base comum (Background) de capacidades que não são elas mesmas estados intencionais."

29 Como se sabe, J. Habermas e K.O. Apel desenvolveram largamente o carácter ilocutório do acto de fala na sua dimensão comunicativa. No entanto, ao aceitarem a distinção a que nos referimos - componente proposicional, componente comunicativa - pressupõem já claramente a constituição do objecto e mesmo o nivel cognitivo. Por este motivo os seus estudos, embora possam conter interessantes indicações, mostram-se claramente insuficientes e inadequados para satisfazer o trabalho que nos propomos - o esclarecimento da experiência - uma vez que caracterizámos esta como ante-predicativa, pré-objectual e pré-cognitiva. 
Notemos, no entanto, que a questão comum transmitida pela tradição não é necessariamente, nem a maioria das vezes, formulada de modo expresso. Dissemos anteriormente que a tradição é constituída por "respostas sem questão" ou, mais exactamente, por respostas que, ao velarem as questões de onde surgiram, se velam a si próprias como respostas expressas. Nesta medida, quando locutor e auditor se situam no seio de uma mesma tradição, uma vez que a questão não é explicitada, todo o trabalho do diálogo através do qual se determina o sentido ou significação do enunciado não é igualmente expressamente formulado; ele é sempre virtualmente pressuposto, podendo todavia vir a ser eventualmente actualizado de modo explícito.

Como a questão não é expressamente formulada, são sempre possíveis equívocos, dificuldades de interpretação, relativamente à questão que está em causa e é pressuposta. $\mathrm{O}$ auditor pode interpretar o enunciado a partir da resposta a uma questão diferente daquela a que o locutor respondeu; a interpretação realiza-se então de modo defeituoso. Naturalmente que a simples mostração ostensiva do ente não pode obviar à dificuldade a que nos referimos; se o "estado de descoberto" do ente (comunicado pelo enunciado de experiência) não é uma sua determinação ôntica, mas reenvia para a conformidade (ou não) com um determinado comportamento humano no mundo, então o enunciado só poderá ser correctamente interpretado quando esse comportamento for compreendido como resposta a uma questão precisa. Ora, este trabalho de esclarecimento, visando evitar o equívoco, só pode ser efectuado através da formulação explícita do diálogo implícito, diálogo que pretende patentear, caso seja necessário, a pressuposta questão comum a locutor e auditor. Como dissemos, a significação de um enunciado, mesmo de experiência, não é autónoma, eala só pode ser determinada pelo recurso a outros enunciados através da conversação, neste caso visando esclarecer a relação pergunta/resposta ou, mais exactamente, visando estabelecer acordo a respeito da questão, agora expressamente formulada subsumindo locutor e auditor.

\section{VII - O carácter originário da conversação na experiência}

Agora bem, repetimos, se questionar é abrir possibilidades - as várias respostas possíveis - e responder é eleger uma dessas possibilidades enquanto fundamento do não-ser das outras, então um enunciado, na medida em que implica uma resposta entre outras, nunca pode ser considerado isoladamente de todas as outras respostas possíveis.

Um enunciado, mesmo de experiência, reenvia sempre para outros possíveis enunciados, outras respostas possíveis, outros possíveis modos de encontrar o ente.

Se um enunciado de experiência, devido à tradição, se encontra sempre no seio de um espaço de diálogo segundo a relação pergunta/resposta, então a determinação do seu sentido objectivo exige a discussão entre as várias pos- 
sibilidades abertas pelo questionar. Precisamente tal discussão visa esclarecer porque uma possibilidade (resposta) foi eleita enquanto fundamento do não-ser das outras, tentando articulá-las unitariamente em vista de um (possível) acordo. Só então o sentido objectivo do enunciado de experiência, isto é, as suas condições de satisfação, pode ser determinado.

Um enunciado não possui um sentido objectivo intrínseco, exterior e isolado do diálogo e da discussão. É pois impossível determinar o sentido de um enunciado isolado, fazendo a economia da discussão e do diálogo visando o acordo entre locutor e auditório. O sentido é algo que só surge no interior de um espaço dialógico, pressupondo-o. Poderemos afirmar que a conversação é originária e é só através dela que algo como um sujeito se pode, de modo derivado, constituir ${ }^{30}$

A objectividade do enunciado de experiência não é fundada na referência e na predicação, no conhecimento do objecto, como no caso do enunciado teórico, nem numa mítica harmonia a priori entre a imaginação livre o entendimento, harmonia idêntica para todos os homens, como no juízo de gosto para Kant; tal objectividade não é mais do que o possível acordo, no seio de uma comunidade de comunicação, como resultado da discussão e do diálogo entre as várias respostas abertas ${ }^{31}$. A objectividade do sentido não é algo intrínseco ao enunciado, surgindo como um dado inicial, mas o resultado de um processo dialógico.

Para terminar deveremos mesmo questionar-nos a propósito da pertinência da distinção irredutível que Kant estabelece entre juízos de gosto e juízos teóricos. Não será o conhecimento um modo derivado da experiência no mundo e, nessa medida, as dificuldades encontradas a propósito da objectividade do juízo de gosto não acompanharão toda a experiência em geral, incluindo a própria experiência cognitiva?

30 É estranho e divertido verificar que os filósofos na sua quase totalidade, ao restringir o estudo da linguagem à sua dimensão cognitiva, sempre pressupuseram que os homens falavam e escreviam tendo em vista apenas a redacção de tratados filosóficos ou científicos; esquecia-se assim o óbvio, a saber, que qualquer enunciado, enquanto acto de fala, visa em primeiro lugar o entendimento com alguém sobre algo, como nos diz Habermas. Na verdade este "esquecimento" tem profundas raízes na Antiguidade; é o que nos mostra a disputa entre filósofos e sofistas ou entre filosofia e retórica, visando a supremacia na educação da juventude ateniense. Como se sabe, a filosofia, sobretudo a filosofia teorética, levou a melhor nesta disputa, em grande parte devido à obra de Aristóteles. Ora o Estagirita ao distinguir o logos apofântikos (enunciado predicativo), verdadeiro ou falso, do logos não apofântikos, possuindo sentido (semântikos), mas não passível de verdade ou falsidade, considera o primeiro característico da filosofia e do conhecimento científico e deixa o segundo à consideração da retórica e da poética (Da Interpretação 4, 17a). Deste modo o logos apofântikos, o enunciado teorético composto por sujeito e predicado, passa a ser o tema proeminente, quando não exclusivo, da reflexão filosófica que versa a linguagem

31 Diz-nos Gadamer: "pela sua essência mais própria o gosto não é algo privado, mas um fenómeno social de primeiro plano." Wahrheit und Methode, Paul Siebeck, Tuebingen, 1990, p. 41 . 
Mas terá sentido falar de juízos estéticos? Poderá o princípio determinante de um juízo ser meramente subjectivo? Por outras palavras, a compreensão do belo e da arte poderá ser realizada em termos de estética? Tal não nos parece possível.

\section{Résumé}

On prétend établir les rapports entre expérience et communication.

D'abord, on fai un approche à la conception de tradition telle comme elle est exposé par H.G.Gadamer.

On prétend compléter l'idée de tradition présentée par Gadamer et Jauss, en faisant la distinction entre les élements thématiques et les élements non thématiques de la tradition, bien comme en distinguant la situation hérmeneutique, dans laquelle l'interprète se trouve toujours, du travail hérméneutique (exegese). Il faut alors articuler la réponse existentielle (non thématique) humaine avec la tradition.

On montre ainsi que la tradition transmet thématiquement réponses et, de façon non thématique (simplement implicite), questions trans-subjectives qui subsument à la fois locuteur et auditeur. L'expérience, le mode humain de rencontrer l'étant à l'état de découvert, possède ainsi avec nécessité une dimension communicative, trans-subjective. Il n'y a pas des expériences privées ni des expériences muettes, antérieures au discours, à la conversation.

La signification du plus simples énoncé d'expérience implique une double orientation: l'état des choses dans le monde, mais aussi la communication entre locuteur et auditeur. 